Athmen Zenati* and Yang-Kyoo Han

\title{
Synthesis and characteristics of novel azo-based diblock copolymers and their self-assembly behavior via solvents and thermal annealing
}

DOI 10.1515/epoly-2017-0042

Received February 27, 2017; accepted April 15, 2017; previously published online June 16, 2017

Abstract: A series of azo-based diblock copolymers (DBCs) with various compositions were successfully synthesized via reversible addition-fragmentation chain transfer (RAFT) polymerization in anisole with PCAEMA-CTA (macro-CTA), DOPAM (new acrylamide monomer) and AIBN (initiator). Kinetic studies on diblock copolymerization manifested a controlled/living manner with good molecular weight control. Structures and properties of monomers and DBCs were determined by ${ }^{1} \mathrm{H}$ nuclear magnetic resonance (NMR), differential scanning calorimetry (DSC) and gel permeation chromatography (GPC). Liquid crystalline (LC) phases and morphological properties were investigated using optical polarizing microscope (OPM), atomic force microscopy (AFM), scanning electron microscopy (SEM) and small-angle X-ray scattering (SAXS). Experimental results demonstrated that the prepared PCAEMA-CTA and DBCs possessed low polydispersity index $(\leq 1.37)$. All DBCs revealed sharp endothermic transition peaks corresponding to the smectic-to-nematic phase. DBCs with high azo contents showed batonnet textures of the smectic phase whereas DBCs of low azo segments displayed threaded textures of the nematic phase. DBC with 49 wt $\%$ of azo side-chains generated a lamellar compared to DBCs with low azo block ( $\leq 41 \mathrm{wt} \%$ ) or nonazo block ( $\leq 38$ wt $\%$ ) which produced hexagonal-type nanostructures. In addition, all DBCs exhibited reversible trans-cis photoisomerization behavior under UV irradiation and dark storage at different intervals of time.

Keywords: azobenzene moiety; azo diblock copolymers; phase transitions; photoresponsive property; self-assembly.

\footnotetext{
*Corresponding author: Dr. Athmen Zenati, PhD, Functional Organic Materials Laboratory (FOML), Department of Chemistry, Faculty of Natural Sciences, Hanyang University, 17 Haengdang-dong, Seongdong-gu, Seoul 133-791, Korea, e-mail: athmen2004@hotmail.com; athmen2004@hanyang.ac.kr Yang-Kyoo Han: Functional Organic Materials Laboratory (FOML), Department of Chemistry, Faculty of Natural Sciences, Hanyang University, 17 Haengdang-dong, Seongdong-gu, Seoul 133-791, Korea
}

\section{Introduction}

In recent years, considerable attention has been paid to azobenzene-containing polymer materials including homopolymers and block copolymers due to the valuable combination of liquid crystals' anisotropy within attractive bulk properties of polymers $(1,2)$. Polymers containing azo-chromophores exhibit anisotropic absorption behaviors with the primary absorption dipole along the molecular long axis and the secondary absorption dipole along the molecular short axis, as a result of alignment of azo dyes which is the same as the nematic liquid crystal host by cooperation motion (3). In addition, block copolymers (BCs) having the interplay between the microphase separation and the elastic deformation of liquid crystal ordering which is defined as supramolecular cooperative motion (SMCM), exhibit more hierarchical structures with photoresponsive features. Generally, such an SMCM is regarded as one of the most effective approaches to control supramolecularly self-assembled nanostructures in liquid crystalline (LC) BCs $(4,5)$.

The BCs tend to microsegregate into ordered microor nanometer-sized domains because of two or more chemically different polymer segments (6). Especially, the $\mathrm{BC}$ with a LC block gives rise to microphase separated morphologies and fast self-assembly into diverse nanostructures such as spheres, cylinders and lamellae by the solvent vapor annealing (SVA) process or thermal treatment of an LC block. Likewise, the azobenzene-based $\mathrm{BC}$ has an advantage of changing its thin film's morphology by the trans-cis photoisomerization of azo chromophores in the $\mathrm{BC}$ under alternating irradiation of UV and visible light $(7,8)$. This photoinduced transformation from one isomer to another by UV-visible light can also cause large changes in the size, the polarity and the shape of the polymers $(9,10)$. Thus, it has long been noted that azobenzene-containing polymers are very widely used for applications such as optical data storage media (ODSM) for digital data (11), liquid crystal displays (LCD), photoswitching, sensors (12), nanotechnology (13), holographic surface relief gratings and photonic memories through the photoinduced trans-cis isomerization of the light-sensitive azobenzene chromophore (14). 
As few scientific research papers are available on the synthesis of crystalline (hard)-crystalline (hard) diblock copolymers (DBCs), this article reveals the synthesis and the characterization of a series of novel LC hard-hard DBCs from the new polyacrylamide with a long alkyl chain, poly(p-dodecylphenyl-N-acrylamide) (PDOPAM) and the side-chain liquid crystalline polymer (SCLCP) containing azobenzene mesogenic side groups, poly(2-[2-(4-cyanoazobenzene-4'-oxy)ethylene-oxy]ethyl methacrylate) (PCAEMA). The article also describes the thermal behavior and morphology of the prepared DBCs having different compositions.

Moreover, these AB-type DBCs are of particular scientific interest because they can generate microphase separation and form well-ordered microdomain nanostructures including sphere, cylinder, lamellar, and cubic structures. The perfect formation of well-ordered nanostructures through self-assembly is based on the selection of the proper structure of polymer, solvent and thermal annealing treatment (15).

The last decade has seen an increase in the current state-of-the-art reviews for LC polymers such as the capability of self-assembly for nanofabrication, photoalignment in LC polymers $(16,17)$, photoinduced chirality (18) and photoinduced orientation of meso-azobenzene groups in polymer films $(19,20)$. This photoinduced orientation allows systems possessing azo-chromophore to be employed as photoswitches that could rapidly and reversibly control the material properties. Besides, the photoinduced orientation of azo groups in LC DBC is much more stable than other materials $(21,22)$. Therefore, the azobenzene-containing DBC is believed to be a material that exhibits optical storage properties (23).

Herein, we will expand our involvement in this emerging area of research especially the molecular design of azobenzene-based DBCs with well-defined phase transitions and their morphologies with various compositions. Lastly, we highlight our findings for the basic understanding of the polymer chemistry of these phenomena.

\section{Materials, measurements and methods}

\subsection{Materials}

4-Aminobenzonitrile (98\%, Sigma-Aldrich, Seoul-Korea) was recrystallized from a mixture of water and ethanol (9/1, v/v) (24). Sodium nitrite $(97+\%$, Sigma-Aldrich, Seoul-Korea), potassium carbonate $(97+\%$, Sigma-Aldrich,
Seoul-Korea), diglyme (99\%, Sigma-Aldrich, Seoul-Korea), phenol (99+\%, Sigma-Aldrich, Seoul-Korea), 2-cyanoprop-2-yl dithiobenzoate (CPDB, 97\%, Sigma-Aldrich, Seoul-Korea), p-dodecylaniline (97\%, Sigma-Aldrich, SeoulKorea) and 2-(2-chloroethoxy) ethanol (99\%, Sigma-Aldrich, Seoul-Korea) were used as received. Tetrahydrofuran (THF, 98\%, Samchun Chemical, Seoul-Korea) was dried over $\mathrm{CaH}_{2}$ and distilled under a nitrogen atmosphere before use. Methacryloyl chloride (97+\%, Sigma-Aldrich, Seoul-Korea) was purified by vacuum distillation to remove an inhibitor. Azoisobutyronitrile (AIBN, Merck Chemicals, Seoul-Korea) was used after recrystallization from methanol, and anisole was used as received (99\%, Sigma-Aldrich, Seoul-Korea).

\subsection{Measurements}

The following instruments were used: a $400 \mathrm{MHz}$ nuclear magnetic resonance (NMR) spectrometer (Bruker, SeoulKorea) using tetramethylsilane (TMS) as a reference solvent. A gel permeation chromatograph (GPC) instrument (Waters, Seoul-Korea) equipped with four waters columns (Styragel HR 0.5, 2, 4 \& 5) and a Waters 2414 refractive index detector using THF as an eluent (flow rate of $1 \mathrm{ml} / \mathrm{min}$ ). A differential scanning calorimeter (DSC-Q 100, TA Instruments, Seoul-Korea). Atomic force microscopy (AFM, Park Systems, Seoul-Korea) using an XE-100 system (advanced scanning probe microscopy) operating in noncontact mode with a 910-NCHR cantilever (force constant; $42 \mathrm{~N} / \mathrm{m}$, resonance frequency; $330 \mathrm{KHz}$ ). A Hitachi-4800 scanning electron microscopy (SEM, Hitachi, SeoulKorea) with a field emission at $1 \mathrm{kV}$. An optical polarizing microscope (OPM-DMRXP-MPS 60, Leica, Seoul-Korea) equipped with a hot stage. Small-angle X-ray scattering (SAXS, conducted on 4C2 beamline, Pohang-Korea) and grazingincidence small angle X-ray scattering (GISAXS, conducted on 3C1 beamline, Pohang-Korea) equipped with an monochromatized X-ray ( $\lambda=1.1747 \AA$ ) with grazing incident angles ranging from 0.10 to $0.23^{\circ}$ and the SCX (4300165/2 CCD detector, Princeton Instruments). A cary 50 Bio UV-Visible spectrophotometer (Varian, Seoul-Korea).

\subsection{Synthesis of new monomer, p-dodecylphenyl-N-acrylamide (DOPAM)}

A (12 g, $0.046 \mathrm{~mol})$ amount of p-dodecyl-aniline was dissolved in methylene chloride (MC) solvent (100 mm). The solution was poured into a $250 \mathrm{ml}$ 2-neck round flask, and triethylamine (20\% excess) was added dropwise through a dropping funnel for $10 \mathrm{~min}$ (25). A solution containing 
acryloyl chloride ( $3.8 \mathrm{ml}, 0.047 \mathrm{~mol})$ in $\mathrm{MC}(30 \mathrm{ml})$ was gradually added dropwise to the mixed solution for $20 \mathrm{~min}$ under a nitrogen atmosphere. Meanwhile, the solution was cooled in an ice bath to prevent the temperature of the reaction mixture from rising above $5^{\circ} \mathrm{C}$. After $6 \mathrm{~h}$ of reaction time under $0^{\circ} \mathrm{C}$, the solution was kept at room temperature for a further $10 \mathrm{~h}$ of reaction. Upon completion of the reaction, the solution was passed through a filter paper to eliminate the precipitated salt, and then the solvent was evaporated from the filtrate on an evaporator. The obtained solid was dissolved in MC $(100 \mathrm{ml})$ and added to a separatory funnel with $10 \%$ aqueous $\mathrm{NaHNO}_{3}$ solution $(50 \mathrm{ml})$. The funnel was shaken vigorously and set aside to allow complete separation of the aqueous phase and thereby to remove the unreacted acryloyl chloride. Magnesium sulfate $(1.0 \mathrm{~g})$ was added to the separated MC solution. After being stirred for $5 \mathrm{~h}$, the solution was subjected to filtration to remove the trace amount of water dissolved in the solvent. The MC solution thus obtained was kept on the evaporator, and $\mathrm{n}$-hexane $(100 \mathrm{ml})$ was added. The solution was stirred for $2 \mathrm{~h}$ and the unreacted p-dodecyl aniline was filtered from the solution. The resulted product was recrystallized from methanol to yield a white solid DOPAM monomer (Scheme 1). Yield: $89 \%$, m.p: $101^{\circ} \mathrm{C}$ differential scanning calorimetry (DSC), ${ }^{1} \mathrm{H}$ nuclear magnetic resonance (NMR) ( $\left.\mathrm{CDCl}_{3}, 400 \mathrm{MHz}, \mathrm{ppm}\right): 7.5(\mathrm{~d}, 2 \mathrm{H}), 7.2$ (s,1H), 7.15 (d, 2H), 6.4 (d, 1H), 6.2 (q, 1H), 5.8 (d, 1H), 2.6 (t, 2H), 1.25-1.35 (m, 20H), and 0.93 (t, 3H) (see supporting information, Figures 4 and $8 \mathrm{~B}$ ).

\subsection{Synthesis of the macromolecular chain-transfer agent (PCAEMA-CTA)}

The successful synthesis of poly(2-[2-(4-cyano-azobenzene4'-oxy)ethylene-oxy]ethyl methacrylate) (PCAEMA-CTA) was carried out in anisole using AIBN as initiator and CPDB as starting chain transfer agent (Scheme2). For the reaction,
CAEMA (6.0 g, $0.0158 \mathrm{~mol})$, AIBN ( $8.6 \mathrm{mg}, 0.0526 \mathrm{mmol})$, CPDB (35 mg, $0.1579 \mathrm{mmol}$ ) and $18 \mathrm{ml}$ of anisole were added into a $25 \mathrm{ml}$ Schlenk flask. After $15 \mathrm{~min}$ nitrogen purge under stirring, the flask was sealed and placed into a preheated oil bath at $75^{\circ} \mathrm{C}$ for $24 \mathrm{~h}$. The reaction solution was quenched from liquid nitrogen, diluted by $12 \mathrm{ml}$ of THF and dropped into $500 \mathrm{ml}$ of methanol to precipitate the PCAEMA-CTA. The precipitation was repeated three times. The obtained PCAEMA-CTA (orange powder) was dried in a vacuum oven at room temperature $24 \mathrm{~h}$. The conversion of CAEMA monomer into PCAEMA was $40 \%$. $\mathrm{Mn}=13,800 \mathrm{~g} /$ $\mathrm{mol}, \mathrm{Mw} / \mathrm{Mn}=1.14$ (GPC), ${ }^{1} \mathrm{H}$ NMR $\left(\mathrm{CDCl}_{3}, 400 \mathrm{MHz}\right): 0.8-$ $1.15\left(\mathrm{~d}, 3 \mathrm{H}\right.$, main chain $\left.\mathrm{CH}_{3}\right), 3.8-4.25\left(\mathrm{t}, 8 \mathrm{H}, \mathrm{OCH}_{2} \mathrm{CH}_{2} \mathrm{O}\right)$, 1.7-2.0 $\left(\mathrm{CH}_{3}-\mathrm{CCN}-\mathrm{CH}_{3}\right.$ and main chain $\left.\mathrm{CH}_{2}\right), 6.90(\mathrm{~s}, 2 \mathrm{H}, \mathrm{o}-\mathrm{Ar}$ $\mathrm{H}$ to $\mathrm{OCH}_{2}$ ), 7.41-7.74 (t, 9H, o,m-Ar $\mathrm{H}$ to $\mathrm{CN}, \mathrm{m}-\mathrm{Ar} \mathrm{H}$ to $\mathrm{OCH}_{2}$ and p,o-Ar to SCS), 7.84 (s, 2H, m-Ar H to SCS).

\subsection{Preparation of the azo-based diblock copolymer (PCAEMA-b-PDOPAM)}

A typical reversible addition-fragmentation chain transfer (RAFT) polymerization was employed to fabricate DBCs using the PCAEMA-CTA (Scheme 2). (DOPAM) (280 mg, $0.898 \mathrm{mmol})$, AIBN (1.85 mg, $0.0112 \mathrm{mmol})$ and PCAEMACTA $(\mathrm{Mn}=13,800 \mathrm{~g} / \mathrm{mol}, 310 \mathrm{mg}, 0.0224 \mathrm{mmol})$ were added into a $10 \mathrm{ml}$ Schlenk flask. Then anhydrous anisole $(2.8 \mathrm{ml})$ was added to the mixture. After a $30 \mathrm{~min}$ nitrogen purge, the flask was flame-sealed and placed in an oil bath. The reaction was held at $70^{\circ} \mathrm{C}$ for $72 \mathrm{~h}$. After a while, the reaction solution was diluted with THF ( $3 \mathrm{ml}$ ) and precipitated into $(250 \mathrm{ml})$ methanol. The precipitation procedure was repeated twice and the light orange $\mathrm{DBC}$ was dried in a vacuum oven for $24 \mathrm{~h}$ at $\left(40^{\circ} \mathrm{C}\right)$. The conversion of the DOPAM into block was $48 \%$ after $72 \mathrm{~h}$ of polymerization time. $\mathrm{Mn}=19,800 \mathrm{~g} / \mathrm{mol}$ and $\mathrm{Mw} / \mathrm{Mn}=1.19$ (GPC). Other DBCs of various compositions were prepared using similar procedures $(26,27)$.

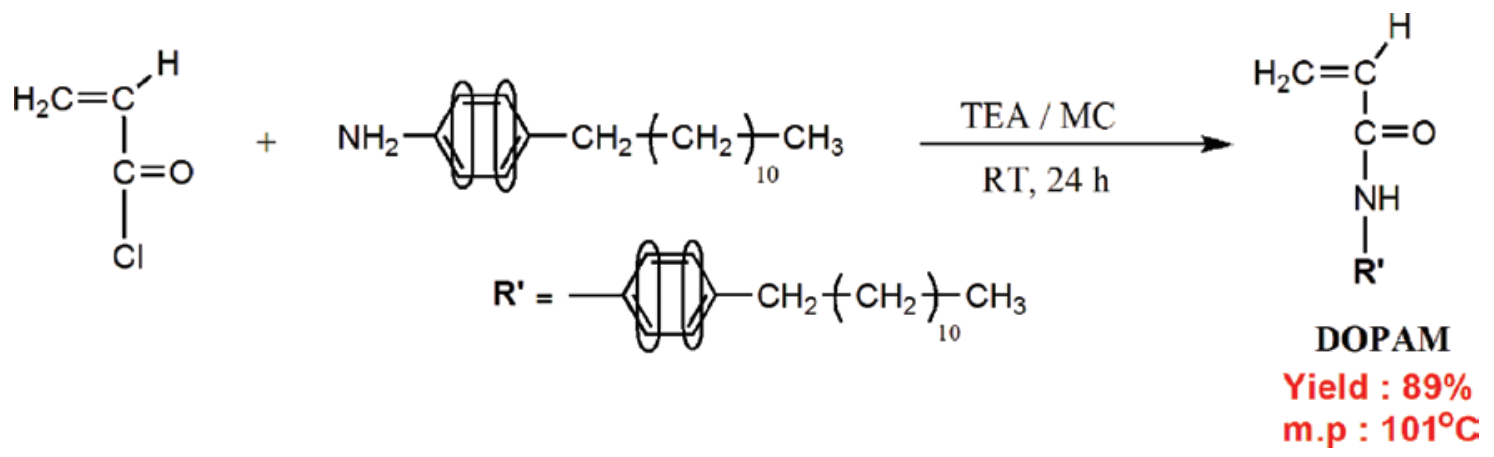

Scheme 1: Synthesis of a new long alkyl chain acrylamide monomer (DOPAM). 

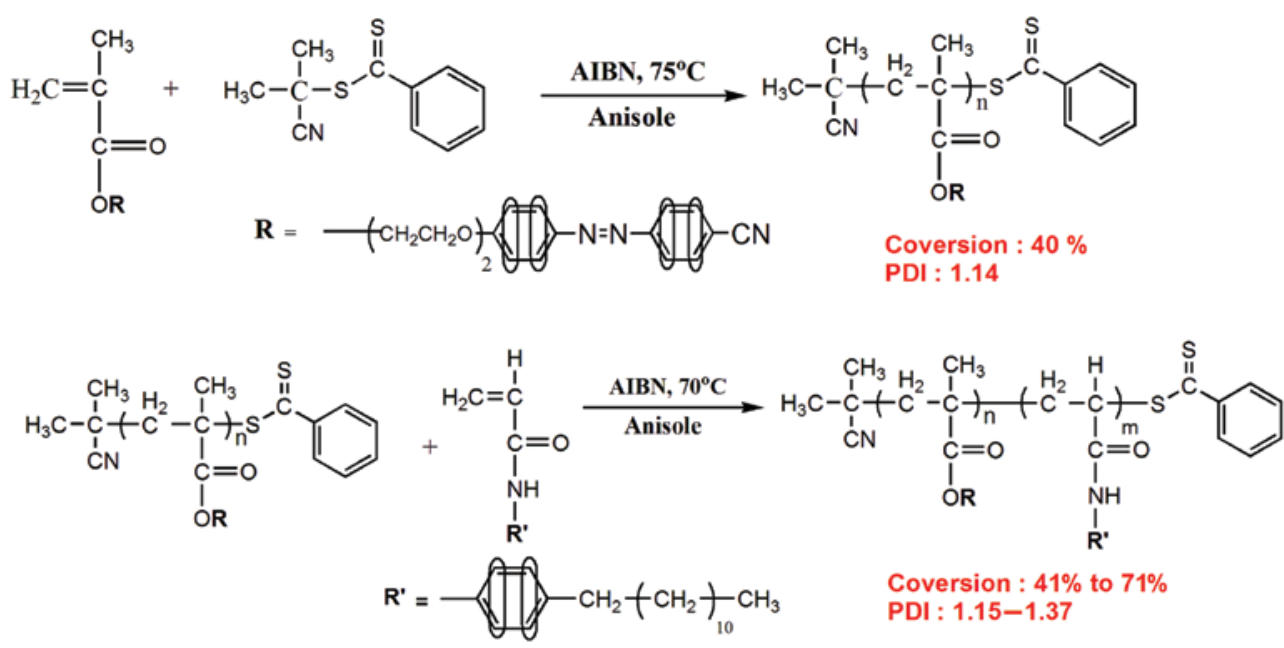

Scheme 2: Synthetic route to the macromolecular chain transfer agent (PCAEMA-CTA) and diblock copolymers.

\subsection{Thin films preparation}

Thin films of the prepared DBCs were prepared by spin coating the $1.0 \mathrm{wt} \%$ polymer solution in THF onto silicon wafer at $3000 \mathrm{rpm}$ for $1 \mathrm{~min}$ (28). Then the thin films were either thermally annealed in the vicinity of $110^{\circ} \mathrm{C}$ or solvent vapor annealed under the mixed solvent vapor of THF/cyclohexane $(70 / 30, v / v)$ in a covered Petri dish for $24 \mathrm{~h}$ (29). The surface morphology of the annealed thin films was investigated by AFM and SEM.

\section{Results and discussion}

\subsection{Synthesis and characterization}

RAFT polymerization has proved to be a powerful technique to synthesize the macromolecular chain transfer agent (PCAEMA-CTA) from the LC monomer with azobenzene moiety (CAEMA) and prepare diblock copolymers with two hard blocks built up from the azo block and the long alkyl chain polyacrylamide block (PDOPAM). The PCAEMA-CTA with a well-controlled number-average molecular weight $(\mathrm{Mn}=13,800 \mathrm{~g} / \mathrm{mol})$ and a narrow polydispersity index (PDI, Mw/Mn=1.14), was first prepared by carefully adjusting the feed molar ratio of 2-(4-cyanoazobenzene-4'-oxy)ethylene-oxy]ethyl methacrylate (CAEMA) monomer, 2-cyanoprop-2-yl-1-dithionaphthalate (CPDN) RAFT agent and azoisobutyronitrile (AIBN) initiator in anisole solution at $75^{\circ} \mathrm{C}$ for $24 \mathrm{~h}\left([\mathrm{CAEMA}]_{0}:[\mathrm{CPDN}]_{0}\right.$ $\left.:[\mathrm{AIBN}]_{0}=300: 3: 1\right)$.

In order to investigate the influence of molecular weight on phase-transition temperatures, a series of azobenzene-containing side-chain liquid crystalline DBCs of different compositions were synthesized by changing the molar ratio of monomer/maco-CTA ([DOPAM $]_{0} /$ $[\text { PCAEMA-CTA }]_{0}$ in the presence of fixed AIBN concentration in anisole solution at $70^{\circ} \mathrm{C}$ for 3 days (Table 1). The number-average molecular weight and the polydispersity index of the resulting DBCs increased with increasing DOPAM monomer concentration. This indicates that the diblock polymerization via RAFT is a controlled/living process.

Figure $1 \mathrm{~A}$ and $\mathrm{B}$ displays the ${ }^{1} \mathrm{H}$ NMR spectrum for the macromolecular chain transfer agent PCAEMA-CTA and the DBC-2 as an example. The chemical constitution of the designed DBCs was estimated from the ratio of the indicated characteristic peaks in their ${ }^{1} \mathrm{H}$ NMR spectrum. The Mn values and the contents of azobenzene in the DBCs are summarized in Table 1.

Figure 2 shows typical GPC curves of the PCAEMA-CTA and the resulting DBCs. The GPC curves signify successful initiation and growth of the second block PDOPAM. All the GPC traces for the designed DBCs shifted linearly to high molecular weights with increasing the second monomer DOPAM feed ratio from 20 to 140 mol (molar ratios) versus PCAEMA-CTA, indicating a well-controlled/ living manner of RAFT polymerization. All obtained DBCs have a narrow molecular weight distribution and a unimodal peak, proving that the PCAEMA-CTA performed as a chain extender to form the second block with no significant amounts of free polymer as a side reaction. Additionally, the conversion of acrylamide monomer DOPAM for RAFT polymerization reached the highest value of $71 \%$ at high monomer concentration (supporting information, Figure 7). Obviously, the molecular weights Mn(GPC)s of the obtained DBCs were very close to the theoretical values 
Table 1: Experimental conditions and characteristics of the synthesized polymers.

\begin{tabular}{|c|c|c|c|c|c|c|c|c|c|}
\hline $\begin{array}{l}\text { Polymer } \\
\text { (Azo.\%) }\end{array}$ & $\begin{array}{r}\left.{\text { [DOPAM }]_{0} /[\text { PCAEMA- }} \text { CTA }\right]_{0} /[\text { AIBN }]_{0}{ }^{c}\end{array}$ & $\begin{array}{l}\text { Reaction } \\
\text { time (h) }\end{array}$ & $\begin{array}{r}\text { Solvent } \\
\text { (anisole) w.\% }{ }^{d}\end{array}$ & $\begin{array}{r}\text { Conversion } \\
(\%)^{\mathrm{e}}\end{array}$ & $\begin{array}{r}M n \\
(G P C)^{f}\end{array}$ & $\begin{array}{l}\text { Mn }\left({ }^{1} \mathrm{H}\right. \\
\text { NMR })^{g}\end{array}$ & Mn $(\text { calcd })^{\mathrm{h}}$ & $\begin{array}{r}\mathrm{Mw} / \mathrm{Mn} \\
(\mathrm{GPC})^{\mathrm{i}}\end{array}$ & Azo. $\%$ \\
\hline Macro-CTA & $100: 1: 1 / 3$ & 24 & 25 & 40 & 13,800 & - & 14,100 & 1.14 & 100 \\
\hline $\mathrm{DBC} 1(81)^{\mathrm{b}}$ & $20: 1: 1 / 2$ & 72 & 10 & 42 & 16,900 & 18,100 & 16,800 & 1.15 & 81 \\
\hline DBC 2 (69) & $40: 1: 1 / 2$ & 72 & 10 & 48 & 19,800 & 20,100 & 19,900 & 1.19 & 69 \\
\hline $\mathrm{DBC} 3(62)$ & $50: 1: 1 / 2$ & 72 & 10 & 50 & 21,900 & 21,900 & 21,600 & 1.21 & 62 \\
\hline DBC 4 & $80: 1: 1 / 2$ & 72 & 10 & 54 & 27,200 & 26,700 & 27,700 & 1.23 & 49 \\
\hline DBC 5 (41) & 100: $1: 1 / 2$ & 72 & 10 & 63 & 33,700 & 32,900 & 33,600 & 1.33 & 41 \\
\hline DBC $6(28)$ & $140: 1: 1 / 2$ & 72 & 10 & 71 & 48,600 & 45,000 & 48,500 & 1.37 & 28 \\
\hline
\end{tabular}

a macro-CTA, macromolecular chain transfer agent (PCAEMA-CTA); ${ }^{\mathrm{b} D B C}$, diblock copolymer; 'Feed molar ratio: [DOPAM], monomer; [AIBN] $]_{0}$ azoisobutyronitrile; [PCAEMA-CTA] $]_{0}$, basis of polystyrene standards. ${ }^{\mathrm{g}}$ Determined by ${ }^{1 \mathrm{H}} \mathrm{NMR}$. ${ }^{\mathrm{h}}$ Calculated from the equation (Eq. 1). iDetermined by GPC. AIBN was used as initiator. Block copolymerization temperature $=70^{\circ} \mathrm{C}$.

[Mn(th)s]. The theoretical molecular weight $[\mathrm{Mn}(\mathrm{th})]$ was calculated according to the following equation.

$$
\begin{aligned}
& M_{n(t h), \text { DBC }}=M_{n(t h), \text { PCAEMA-CTA }}+\frac{[\text { DOPAM }]_{0}}{[\text { PCAEMA-CTA }]_{0}} \times M_{w, \text { DOPAM }} \\
& \quad \times \text { Concersion }
\end{aligned}
$$

$\mathrm{M}_{\mathrm{n}(\mathrm{th})}$ is the theoretical molecular weight of the macromolecular chain transfer agent PCAEMA-CTA, whereas $\mathrm{M}_{\mathrm{w}}$ is the molecular weight of the DOPAM monomer. $[\text { DOPAM }]_{0}$ and $[\text { PCAEMA-CTA }]_{0}$ were the initial concentrations of DOPAM and PCAEMA-CTA, respectively. The PDI values of the prepared $\mathrm{DBCs}$ were relatively narrow as 1.15-1.37 in all cases (Table 1).

\subsection{Phase transition behaviors and LC textures}

The phase-transitions and LC textures of the prepared polymers were determined by means of DSC and OPM. In Figure 3, typical second heating DSC scans of the homopolymer (PCAEMA-CTA) and its corresponding azo diblock copolymers are well highlighted. As marked in Figure 3A, PCAEMA-CTA exhibited a glass transition temperature $\left(\mathrm{T}_{\mathrm{g}}\right)$ in the vicinity of $43^{\circ} \mathrm{C}$ and two endothermic and exothermic peaks during both heating and cooling. The sharp and strong peak at $99^{\circ} \mathrm{C}(3.1 \mathrm{~J} / \mathrm{g})$ was assigned to smectic-to-nematic phase transition $\left(T_{\mathrm{S}-\mathrm{N}}\right)$, while the weak transition at $176^{\circ} \mathrm{C}$ is attributed to nematic-to-isotropic transition $\left(T_{\mathrm{N}-\mathrm{I}}\right)$. On the other hand, all DBCs displayed a single glass transition temperature $\left(\mathrm{T}_{\mathrm{g}}\right)$ around $73^{\circ} \mathrm{C}$ and different LC phase transitions as compared to the homopolymer PCAEMA-CTA. The first three DBCs (Figure 3B-D) exhibited relatively strong and sharp endothermic transition peaks $\left(T_{\mathrm{S}-\mathrm{N}}\right)$ at $114^{\circ} \mathrm{C}, 116^{\circ} \mathrm{C}$ and $117^{\circ} \mathrm{C}$, respectively. In contrast, the $\mathrm{DBCs}$ (Figure $3 \mathrm{E}-\mathrm{G}$ ) with low composition of LC block displayed week endothermic peaks $\left(\mathrm{T}_{\mathrm{S}-\mathrm{N}}\right)$ at $120^{\circ} \mathrm{C}, 121^{\circ} \mathrm{C}$ and $123^{\circ} \mathrm{C}$, especially the DBC with the lowest LC content of $28 \mathrm{wt} \%$ (Figure 3G) that had a very weak feature. Indeed, all the designed DBCs showed a broad melting temperature $\left(\mathrm{T}_{\mathrm{m}}\right)$ between $223^{\circ} \mathrm{C}$ and $240^{\circ} \mathrm{C}$. As revealed in the DSC spectrum, the endothermic transitions for the diblock systems moved slightly upwards and decreased its strength as the content of the LC block decreases from $81 \mathrm{wt} \%$ to $28 \mathrm{wt} \%$ (Table 2). From recorded data in Table 2 with supporting information in Figure 9, the phase transition enthalpies of LC decreased and the melting point $\left(\mathrm{T}_{\mathrm{m}}\right)$ enthalpies increased with an increase of the second block content (PDOPAM). This result was in good agreement with our expectation.

To investigate the optical textures of the LC phases for the obtained polymers, the photomicrographs under crossed polarizers for the LC monomer CAEMA, homopolymer PCAEMA-CTA and DBCs were taken at different temperatures during the first heating and cooling cycle using OPM, as shown in Figure 4. As observed, the CAEMA exhibited nematic texture with fine thread-like fibrils at $116^{\circ} \mathrm{C}$ upon cooling the monomer from the isotropic phase without any thermal annealing (Figure 4A). Further cooling to $45^{\circ} \mathrm{C}$ and annealing for $2 \mathrm{~h}$, the threaded texture is transformed into the smectic phase with a typical fan-shaped focal conic texture (Figure 4B). This proved that the rate of the developing LC phase is very slow. In the case of PCAEMA-CTA, nematic texture with the appearance of thread-like fibrils was the first LC phase that appeared at $112^{\circ} \mathrm{C}$ by cooling the sample from the isotropic phase after $1 \mathrm{~h}$ of thermal annealing at $140^{\circ} \mathrm{C}$ (Figure $4 \mathrm{C}$ ). In addition, a significant increase in the number of fibrils was observed upon cooling to $45^{\circ} \mathrm{C}$ (OPM image not shown). Subsequently, annealing the PCAEMA-CTA at $45^{\circ} \mathrm{C}$ for $1 \mathrm{~h}$ transformed the fibrils into the smectic structure with a typical rod-like texture (Figure 4D). 

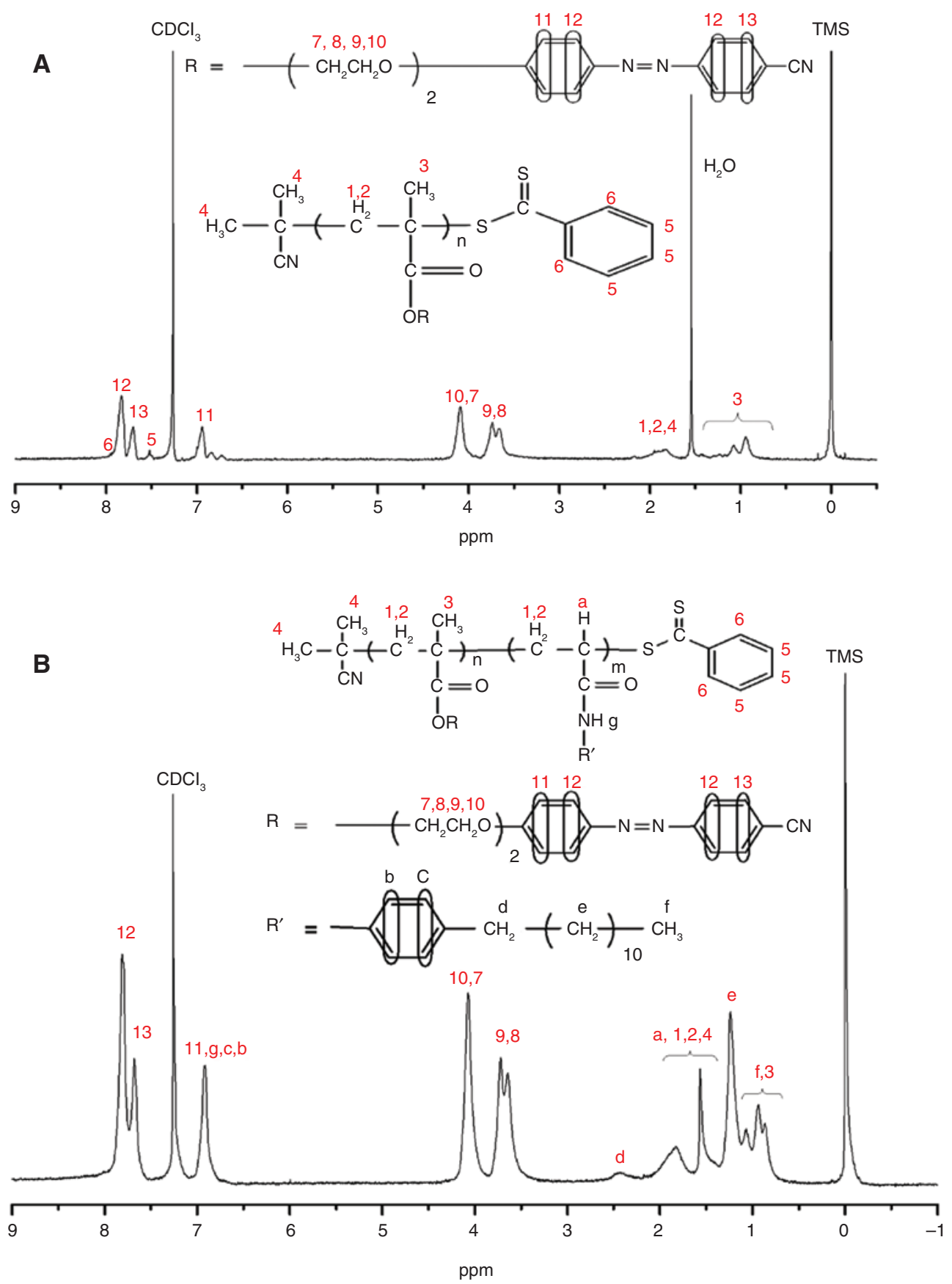

Figure 1: ${ }^{1} \mathrm{H}$ NMR spectrum of $(\mathrm{A})$ the macromolecular chain transfer agent (PCAEMA-CTA) and (B) the diblock copolymer (DBC-2) in $\mathrm{CDCl} 3$ solvent.

On the contrary, the DBCs were annealed for several hours to develop their LC textures. The annealing times for the DBC-5 and DBC- 6 with low LC content block ( $41 \mathrm{wt} \%$ and $28 \mathrm{wt} \%$ ) were longer than annealing times for those with high LC content. The DBCs with $81 \mathrm{wt} \%, 69 \mathrm{wt} \%, 62 \mathrm{wt} \%$ and $49 \mathrm{wt} \%$ of LC blocks exhibited the batonnet textures of the smectic phase by annealing the samples for $3 \mathrm{~h}$ at $240^{\circ} \mathrm{C}$ and slow cooling to the lower temperature ranging from $112^{\circ} \mathrm{C}$ to $47^{\circ} \mathrm{C}$. This indicates that the temperature range for the formation of LC phase is very wide. The optical texture of DBC-2 (Figure 4E) shows an example. Subsequently, annealing the diblock copolymers DBC-1, $-2,-3$ and -4 at $47^{\circ} \mathrm{C}$ for $1 \mathrm{~h}$ changed the batonnet textures, smectic phase to another more ordered smectic phase, suggesting smectic- $\mathrm{C}$ phase (Figure 4F). This remarkable result indicates that the transformation of isotropic phase into smectic phase takes place in a unique fashion. In contrast, the DBCs with the low concentrations of the LC segments, DBC- 5 and DBC- 6 


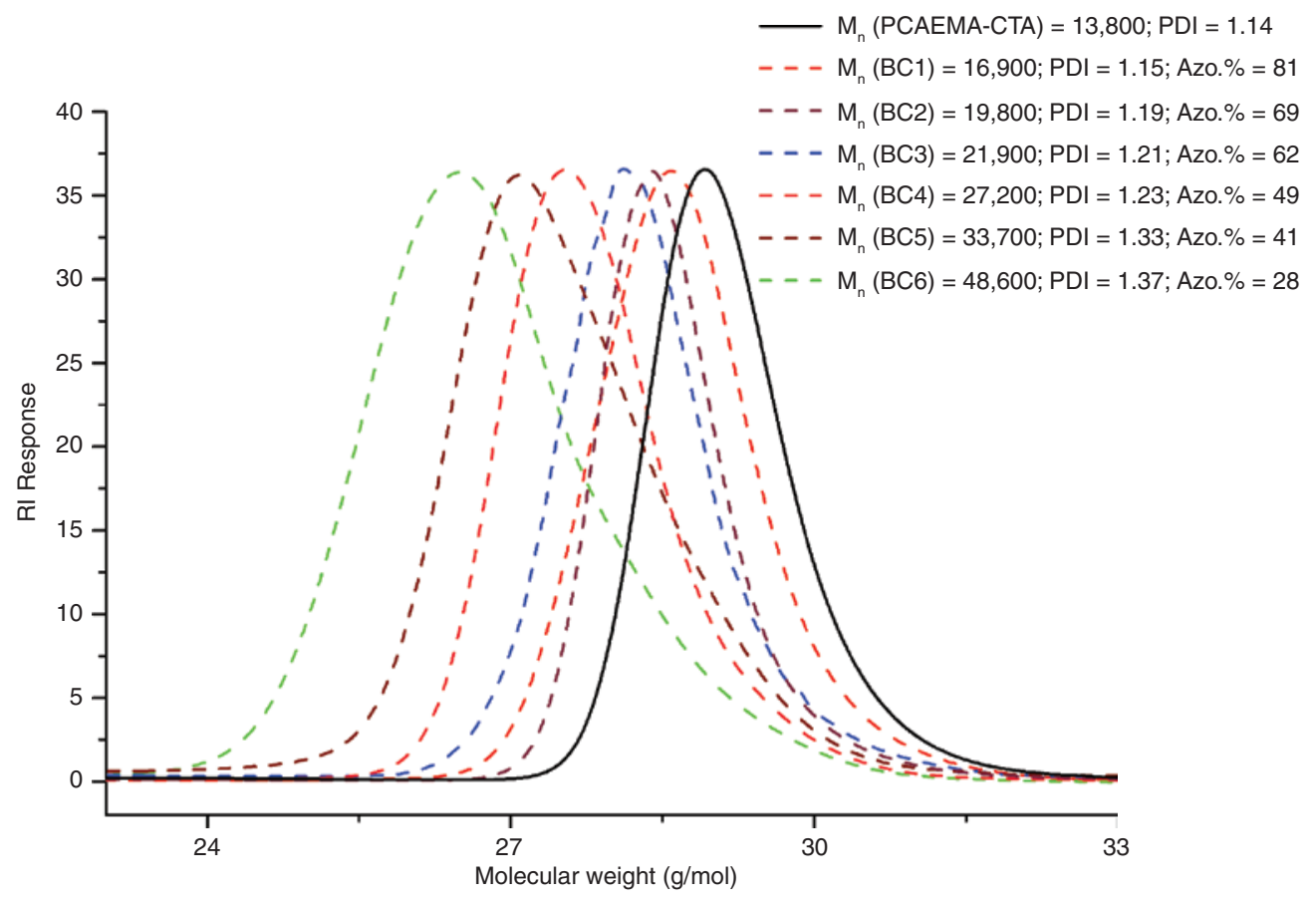

Figure 2: GPC traces for the macromolecular chain transfer agent (PCAEMA-CTA) and diblock copolymers Poly (CAEMA-b-DOPAM) (see Table 1).

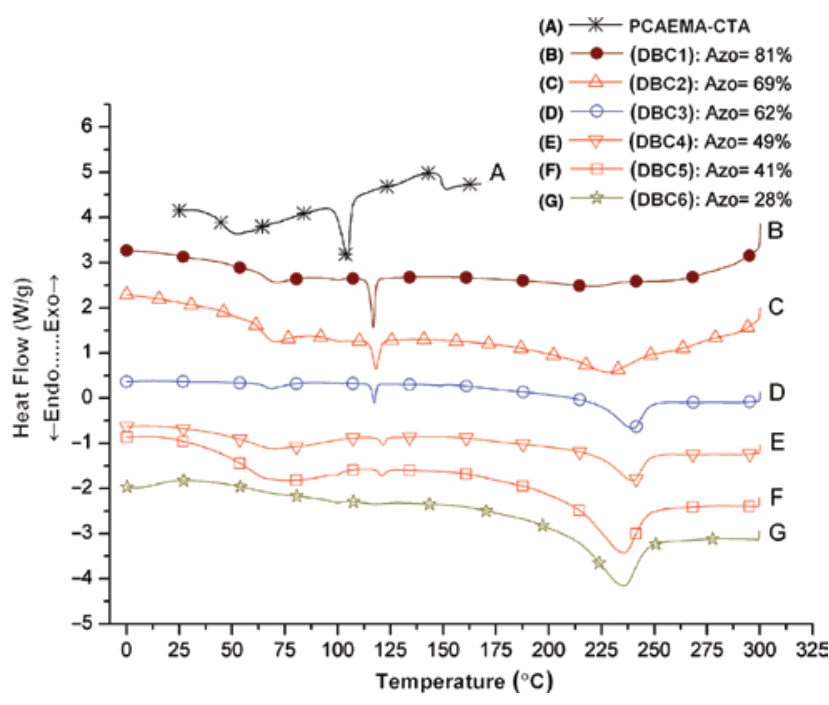

Figure 3: DSC thermograms of the second heating scan for the macromolecular chain transfer agent (PCAEMA-CTA) and diblock copolymers with different contents of the azo block: (A) PCEAMACTA, (B) DBC-1-81\%, (C) DBC- 2-69\%, (D) DBC-3-62\%, (E) DBC-4-49\%, (F) DBC-5-41\% and (G) DBC-6-28\%.

displayed threaded texture typical of nematic phase after $6 \mathrm{~h}$ annealing at $240^{\circ} \mathrm{C}$ to develop their texture and then slow cooling to $121^{\circ} \mathrm{C}$ (Figure $4 \mathrm{G}$ ). On further cooling to lower temperatures, the texture becomes a highly threaded texture (Figure $4 \mathrm{H})$. These results imply that the LC texture of the DBC-5 and DBC- 6 is hard to develop. This shows consistency with DSC measurements (Figure 3F and G).
Table 2: Thermal properties ${ }^{\mathrm{a}}$ of the prepared azo diblock copolymers.

\begin{tabular}{|c|c|c|c|c|c|}
\hline Sample & \multicolumn{3}{|c|}{$\begin{array}{r}\text { Phase transition } \\
\text { temp }\left(\mathrm{T},{ }^{\circ} \mathrm{C}\right), 2 \text { nd } \\
\text { heating }\end{array}$} & \multicolumn{2}{|c|}{$\begin{array}{r}\text { Enthalpy } \\
\text { change } \\
(\Delta \mathrm{H}, \mathrm{J} / \mathrm{g})\end{array}$} \\
\hline (Azo.\%/PDOPAM.\%) & $T_{g}$ & $\mathbf{T}_{\mathrm{lc}}$ & $T_{m}$ & $\Delta \mathrm{H}_{\mathrm{Ic}}$ & $\Delta \mathbf{H}_{\mathrm{Tm}}$ \\
\hline DBC-1 $\quad(81 / 19)$ & 72 & 114 & 223 & 2.6 & 0.9 \\
\hline DBC-2 $(69 / 31)$ & 72 & 116 & 225 & 1.46 & 1.4 \\
\hline DBC-3 $(62 / 38)$ & 72 & 117 & 228 & 1.35 & 6.3 \\
\hline DBC-4 $(49 / 51)$ & 73 & 120 & 232 & 0.42 & 9.6 \\
\hline DBC-5 $\quad(41 / 59)$ & 73 & 121 & 238 & 0.23 & 11.3 \\
\hline DBC-6 $\quad(28 / 72)$ & 74 & 123 & 240 & 0.13 & 11.9 \\
\hline
\end{tabular}

${ }^{\mathrm{a}}$ Transition temperatures and enthalpies on the second heating scan were determined by DSC at $10^{\circ} \mathrm{C} / \mathrm{min} . \mathrm{T}_{\mathrm{g}}=$ glass transition temperature; $\mathrm{T}_{\mathrm{lc}}=$ liquid crystal temperature; $\mathrm{T}_{\mathrm{m}}=$ melting temperature; $\Delta \mathrm{H}_{\mathrm{lc}}$ and $\Delta \mathrm{H}_{\mathrm{Tm}}$ are phase change enthalpy of liquid crystals and enthalpy change of melting, respectively.

\subsection{Morphology of thin films}

Commonly, the chemical incompatibility between the two blocks in the DBC system can form microphase segregated nanostructures (spheres, cylinders, gyroids and lamellae) depending on the relative volume fractions of different segments and the extent of their incompatibility. Besides, LC molecules in the DBC system can be used as ordering actuators to control the alignment of 

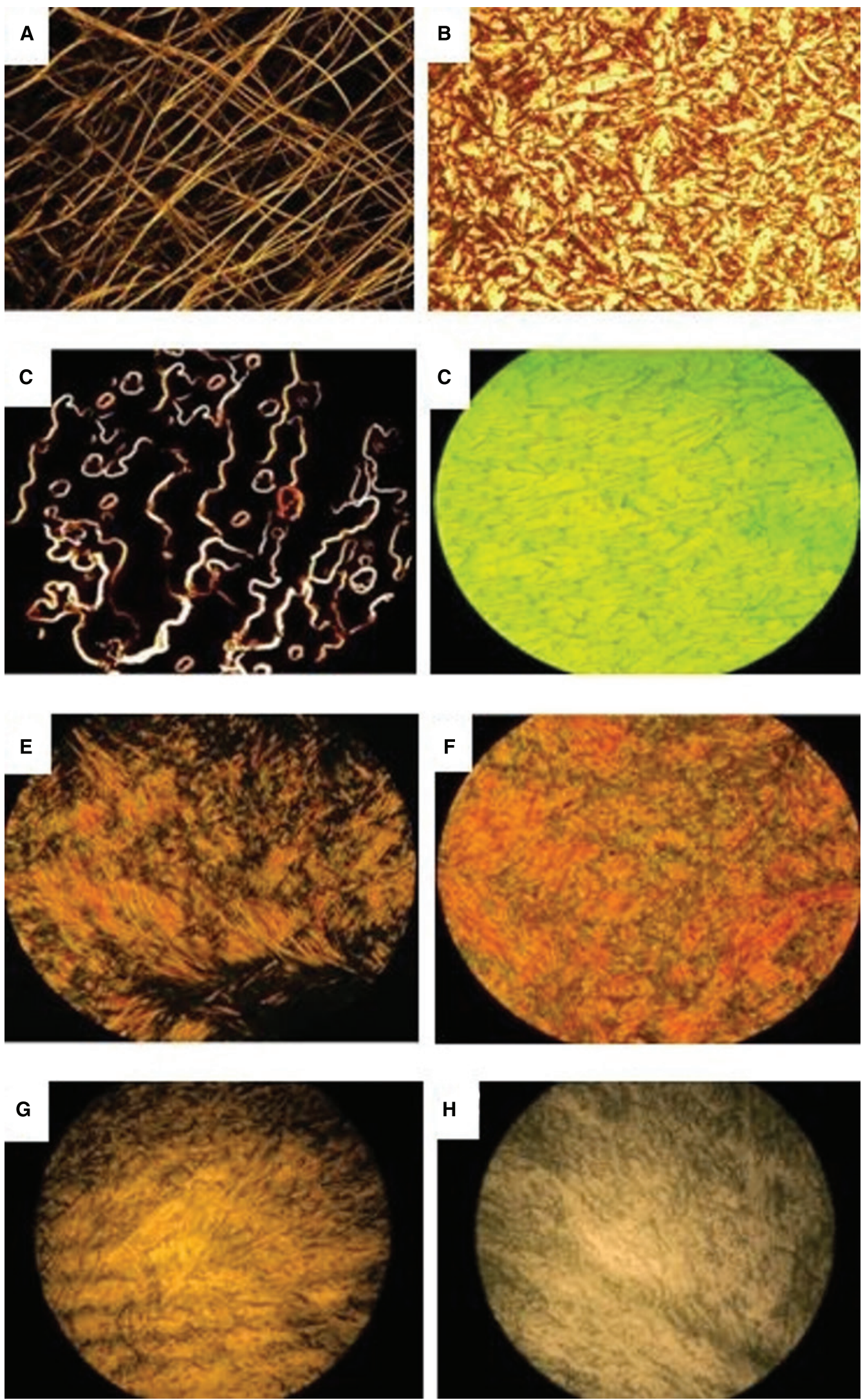

Figure 4: Liquid-crystalline textures of the monomer CAEMA and the synthesized polymers: (A) CAEMA- $116^{\circ} \mathrm{C}$, (B) CAEMA-annealed$45^{\circ} \mathrm{C}-2 \mathrm{~h}$, (C) PCAEMA-CTA- $112^{\circ} \mathrm{C}$, (D) PCAEMA-CTA-annealed- $45^{\circ} \mathrm{C}-1 \mathrm{~h}$, (E) DBC-2-108 ${ }^{\circ} \mathrm{C}$, (F) DBC-2-annealed-47 ${ }^{\circ} \mathrm{C}-1 \mathrm{~h},(\mathrm{G})$ DBC-6-121 ${ }^{\circ} \mathrm{C}$ and (H) DBC-6- annealed- $61^{\circ} \mathrm{C}-4 \mathrm{~h}$. (A and B: magnification $\left.\times 400\right)$; (C, D, E and F: magnification $\left.\times 200\right)$; ( $\mathrm{G}$ and $\mathrm{H}$ : magnification $\left.\times 100\right)$. 

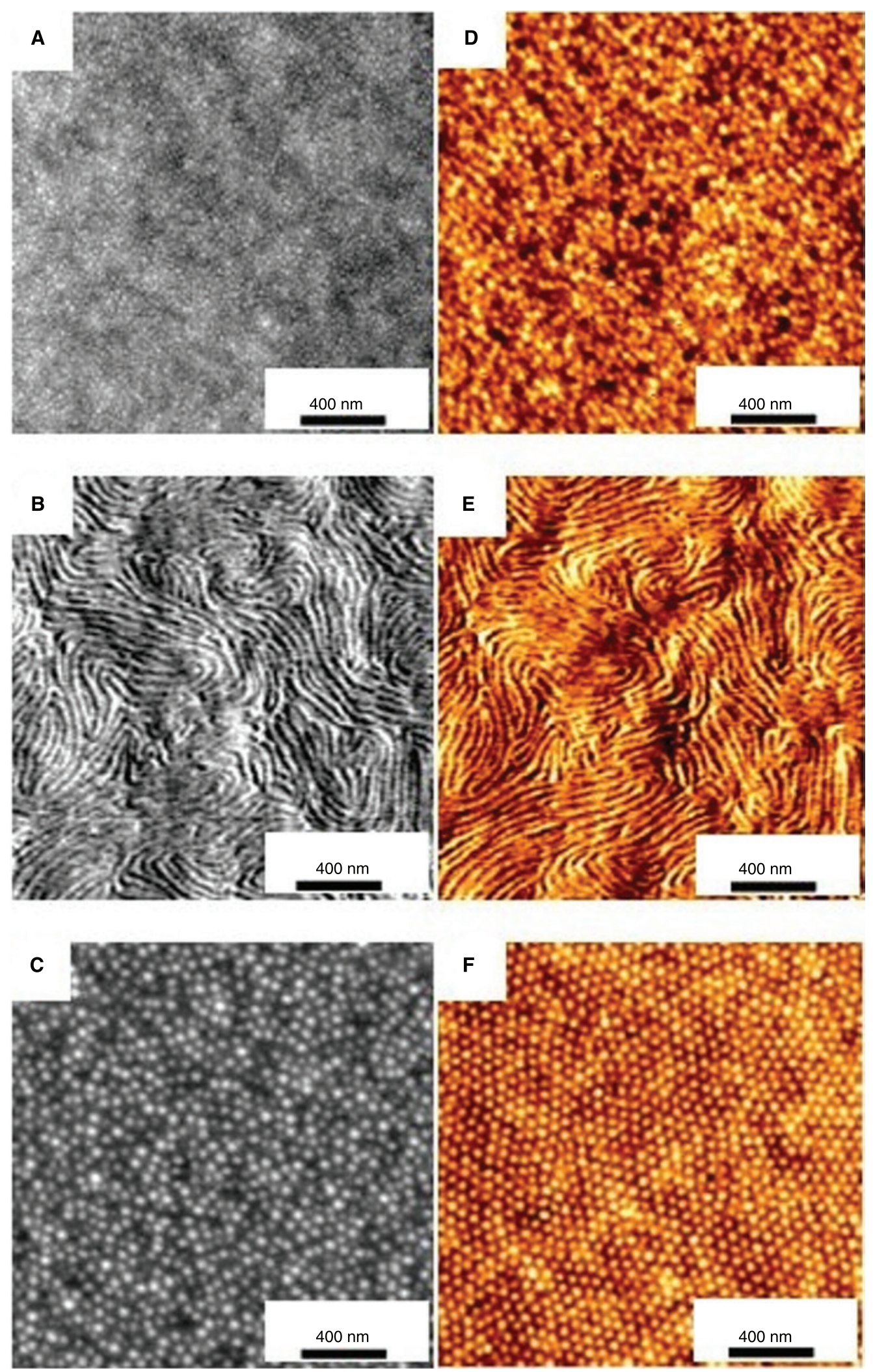

Figure 5: Tapping-mode AFM images (scan size $=2 \times 2 \mu \mathrm{m}$ and scale bar $=400 \mathrm{~nm}$ ) of diblock copolymer thin films with different $L C$ block contents: (A) DBC-2-THF-SC (3000 rpm)- $110^{\circ} \mathrm{C}$, (B) DBC-4-THF-SC (3000 rpm)-110 ${ }^{\circ} \mathrm{C}$, (C) DBC-6-THF-SC (3000 rpm)-110 ${ }^{\circ} \mathrm{C}$, (D) DBC-2-THF-SC (3000 rpm)-solvent-annealing (THF-70\%/cyclohexane-30\%), (E) DBC-4-THF-SC (3000 rpm)-solvent-annealing (THF-70\%/cyclohexane-30\%), (F) DBC-6-THF-SC (3000 rpm)-solvent-annealing (THF-70\%/cyclohexane-30\%). 
microphase separated nanostructures by supramolecular cooperative motion.

Morphological investigation of the DBCs containing mesogenic side chain segments is of particular interest. The morphology of thin films of the prepared DBCs with different ratios of azo dye contents are studied with the aid of tapping-mode AFM and SEM. Thin films were prepared by the spin coating method with thermal annealing or the SVA process. The spin coated films were annealed in the vicinity of the $T_{\mathrm{S}-\mathrm{N}}$ temperature at $110^{\circ} \mathrm{C}$ or annealed under the mixed solvent vapor of THF/cyclohexane for $24 \mathrm{~h}$. The obtained morphologies of poly(CAEMA-b-DOPAM) block copolymer thin films with thickness ranging from $2.7 \mathrm{~nm}$ to $3.2 \mathrm{~nm}$ were easily distinguished from each other.

In the case of thermal annealing treatment, the DBCs (DBC-1, -2 and -3) with high concentration of LC block in the range between $81 \mathrm{wt} \%$ and $62 \mathrm{wt} \%$, exhibited morphology that is consistent with hexagonal-type nanostructures (Figure 5A). In contrast, the AFM image of the DBC-4 (Figure 5B) revealed microphase separated lamellar morphology, as was expected from the volume fraction of LC block content of $49 \mathrm{wt} \%$. The lamellar domain spacing ( $d$ spacing) determined by AFM was $36 \mathrm{~nm}$. The DBC-5 and DBC- 6 also displayed hexagonal morphology which is consistent with the composition ratios of LC block of $41 \mathrm{wt} \%$ and $28 \mathrm{wt} \%$. The hexagonal $d$ spacing and pore size obtained from AFM were $53 \mathrm{~nm}$ and $34 \mathrm{~nm}$, respectively (Figure 5C). Generally, the self-assembly of these DBCs can be explained by interplay processes between regular periodicity of LC ordering and thermally controlled microphase separation caused transfer of ordering of mesogens to nanostructures inside them, which leads to periodically ordered nanostructures $(30,31)$. Such a supramolecular cooperative motion in azo-based DBC thin films is responsible for the formation of microphase separated nanostructures.
On the other side, the nanostructures can be more clearly observed in the solvent vapor annealed films, mainly because of the effect of the mixed solvent vapor of THF/ cyclohexane on the degree of swelling of the two different polymer blocks. After annealing the thin films under the mixed solvent vapor of THF/cyclohexane $(70 / 30, \mathrm{v} / \mathrm{v})$ in a covered Petri dish for $24 \mathrm{~h}$, similar transitions with thermal annealing have been recorded for all DBCs (Figure 5D-F). The SEM micrographs, Figure 6A and B, also show huge similarity in the observation of block copolymer thin film morphologies and revealed nearly equivalent microphase separated domain size to that determined by AFM. These results indicate that the designed DBCs can self-assemble into a variety of nanostructures, depending on the volume fractions of both LC block and non-LC block in the diblock systems. Thus, these polymers can promise to find their diverse applications in advance technologies.

\subsection{Morphology identification via SAXS and GISAXS}

SAXS and GISAXS [monochromatized X-ray $(\lambda=1.1747 \AA)$ : 10-0.23; the SCX: $4300-165 / 2$ CCD detector] experiments were conducted on $4 \mathrm{C} 2$ and $3 \mathrm{C} 1$ beamlines at the Pohang Accelerator Laboratory (Korea) in order to study the microphase separation and the self-assembly of the prepared azo DBCs with different compositions. Figure 7 shows inplane intensity profiles of SAXS and GISAXS patterns as a function of scattering vector for the PCAEMA-b-PDOPAM with three different molecular weights. The $d$ spacing and microdomain structures for the DBCs were estimated from the scattering peaks in their SAXS and GISAXS diffraction patterns (Figure 7A-F). The scattering profiles of DBC-2 (Figure 7A-D) and DBC-6 (Figure 7C-F) suggested hexagonally ordered cylinder nanostructure that is consistent with the characteristic peak ratios of $q / q^{\star}=\sqrt{ } 3$ and $\checkmark 7$ (Figure $7 \mathrm{~A}-\mathrm{F}$ ), where q denotes the length of scattering
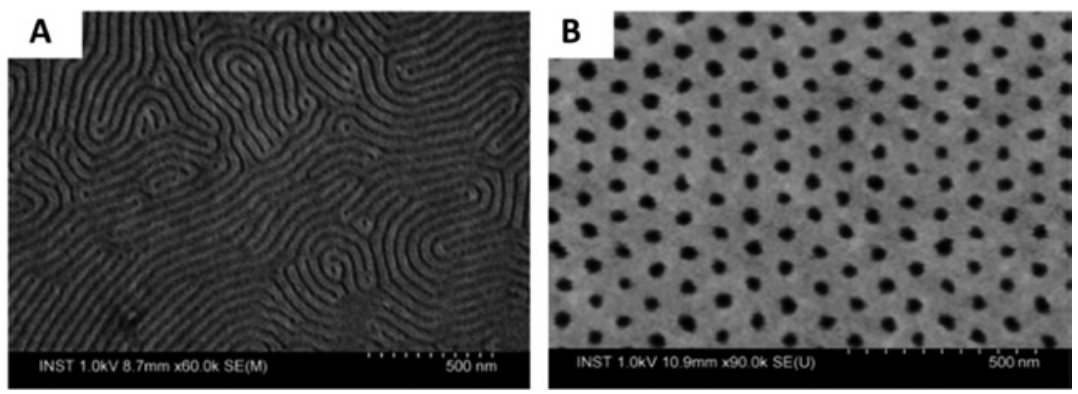

Figure 6: Top-view SEM images of diblock copolymer thin films with different contents (or volume fractions) of azo block: (A) DBC-4-THF-SC (3000 rpm)-solvent-annealing (THF-70\%/cyclohexane-30\%) and (B) DBC-6-THF-SC (3000 rpm)-solvent-annealing (THF-70\%/cyclohexane-30\%). 

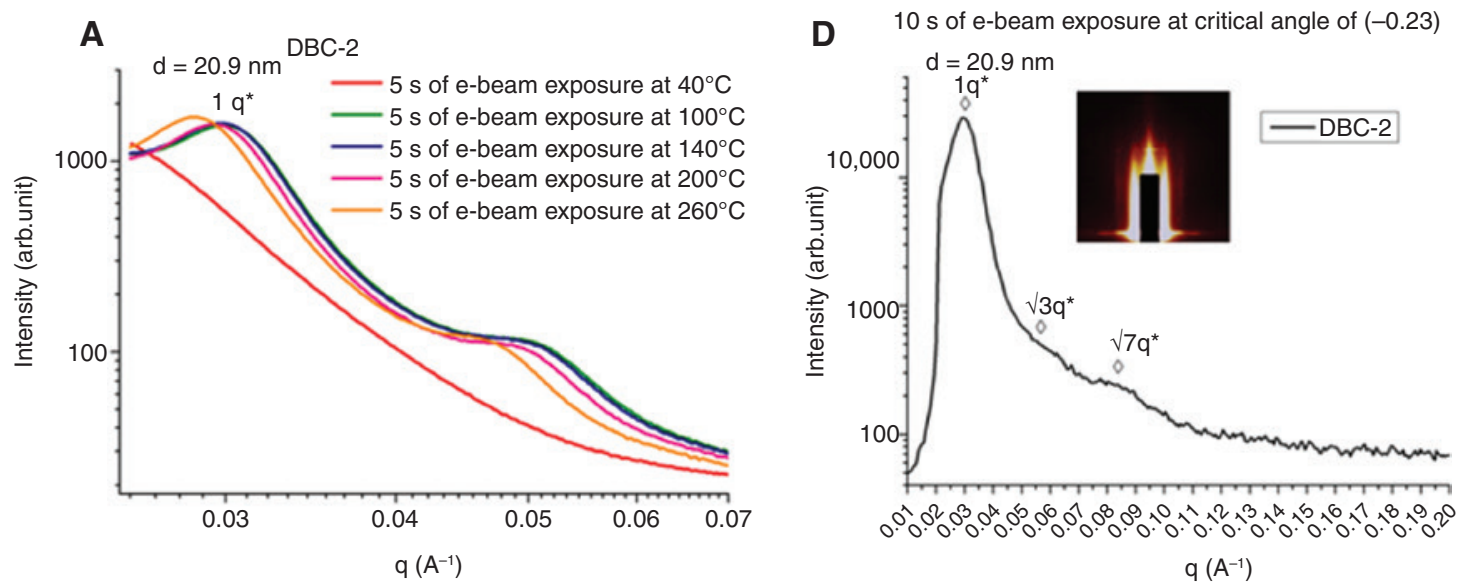

B

E $15 \mathrm{~s}$ of e-beam exposure at critical angle of $(-0.1)$
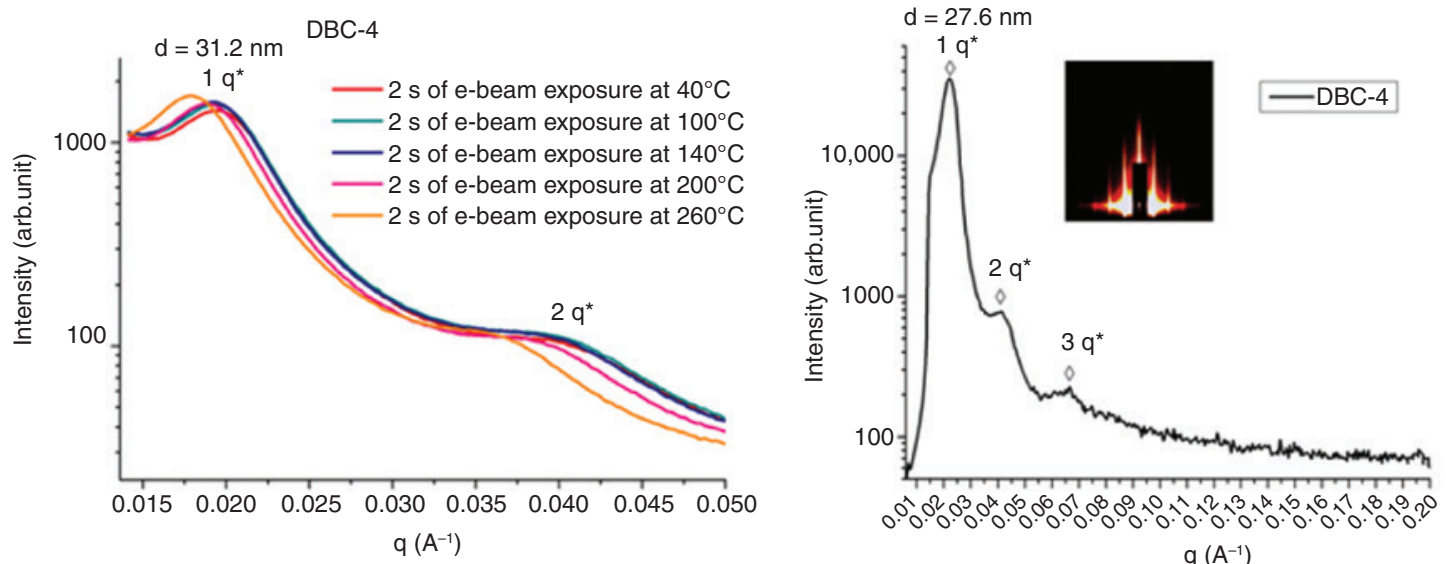

C
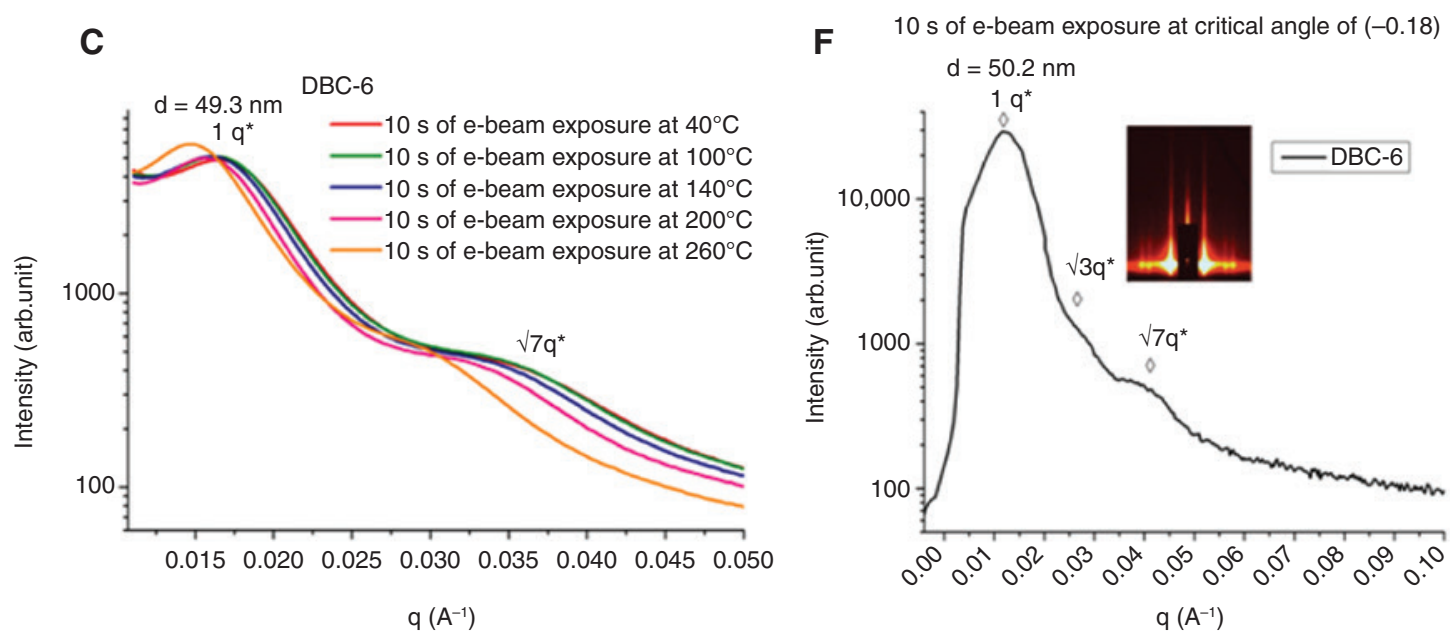

Figure 7: A-B-C; SAXS and D-E-F; GISAXS diffraction patterns for three diblock copolymers (DBC-2, DBC-4 and DBC-6) with different compositions.

vector and $\mathrm{q}^{\star}$ denotes the position of the first diffraction peak. In contrast, the scattering profiles of DBC-4 (Figure $7 \mathrm{~B}-\mathrm{E})$ exhibited a scattering vector of $(\mathrm{V} 1=1)$ and $(\sqrt{ } 4=2)$ times relative to the first-order reflection, suggesting lamellar morphology.

\subsection{Photoresponsive property}

It is well known that azobenzene-containing polymers exhibit reversible trans-cis photoisomerization by irradiation of light with appropriate wavelength and when a 

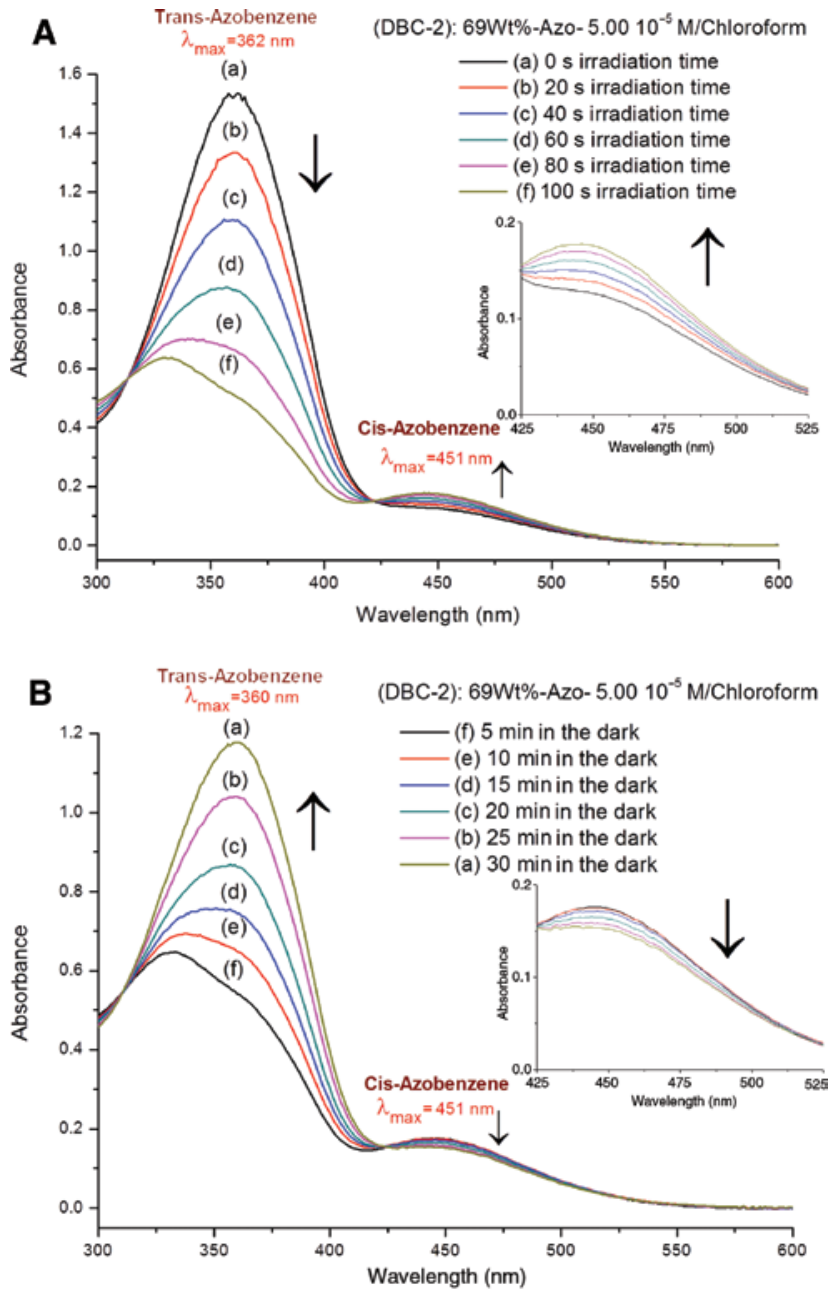

Figure 8: UV-Vis absorption spectra of DBC-2 in chloroform solution under UV light exposure at $365 \mathrm{~nm}(\mathrm{~A})$ and in darkness (B). (A): (a) before irradiation; (b) $20 \mathrm{~s}$ irradiation; (c) $40 \mathrm{~s}$ irradiation; (d) $60 \mathrm{~s}$ irradiation; (e) $80 \mathrm{~s}$ irradiation; (f) $100 \mathrm{~s}$ irradiation. (B): (f) $5 \mathrm{~min}$ in darkness; (e) $10 \mathrm{~min}$ in darkness; (d) $15 \mathrm{~min}$ in darkness; (c) $20 \mathrm{~min}$ in darkness; (b) 25 min in darkness; (a) 30 min in darkness for stability.

chiral azobenzene molecule is doped in cholesteric liquid crystals. The photoresponsive property of the resulting azo-based DBC-2 was investigated by UV-Vis absorption spectra in chloroform solution (Figure 8). As can be seen in Figure 8A, the intensity of the absorption band corresponding to the $\pi-\pi^{\star}$ transition $\left(\lambda_{\max }=362 \mathrm{~nm}\right)$ slightly decreased with its small rise in the $\mathrm{n}-\pi^{\star}$ transition absorption $\left(\lambda_{\max }=451 \mathrm{~nm}\right)$ after $20 \mathrm{~s}, 40 \mathrm{~s}, 60 \mathrm{~s}, 80 \mathrm{~s}$, and $100 \mathrm{~s}$ UV light exposure time. On the other hand, Figure $8 \mathrm{~B}$ shows the stability of the DBC-2 in darkness after $365 \mathrm{~nm}$ UV light exposure. As recorded, the absorption band $\pi$ $\pi^{\star}$ is increased significantly in intensity with its small decrease in the absorption band $n-\pi^{\star}$. Thereby this UVinduced trans-cis isomerization caused variations on the configurational structure, the polarity, and the surface tension of the DBC.

\section{Conclusion}

A well-controlled macromolecular chain transfer agent and a novel series of well-defined azo DBCs were prepared from a monomer with LC p-cyanoazobenzene moiety as both a mesogen and a photoresponsive chromophore, via RAFT polymerization. The newly designed LC DBCs were successfully synthesized from 2-[2-(4-cyano-azobenzene4'-oxy)ethylene-oxy]ethyl methacrylate (CAEMA) and p-dodecylphenyl-N-acrylamide (DOPAM) by RAFT polymerization using CPDB as the starting chain transfer agent and AIBN as the initiator. The molecular weights of the LC DBCs increased linearly with conversion, indicating a controlled/living manner of RAFT polymerization. All the DBCs displayed narrow PDI, $\mathrm{Mw} / \mathrm{Mn} \leq 1.37$, and showed different features due to their varied LC contents. The DBCs with high LC contents displayed strong and sharp endothermic peaks as compared to those of lower LC contents. Thermal investigation revealed that both the PCAEMA-CTA homopolymer and the DBCs have a smectic structure. The DBCs self-assembled into different nanostructures (hexagonal cylinder and lamellar), depending on the azobenzene content and the volume fraction of PDOPAM in the DBC thin films. However, the morphologies of DBC thin films were also related to the solvent and thermal annealing treatment. This result appears to be superior to those of LC DBCs. Furthermore, the prepared LC DBCs exhibited reversible trans-cis photoisomerization behavior under UV light exposure at $365 \mathrm{~nm}$ and in darkness at different intervals of time.

\section{Highlights}

- RAFT polymerization produced DBCs with blocks of well-defined length and narrow molar mass distribution.

- Combination of a mesogenic unit with a long alkyl chain enhanced the microphase separation in DBCs.

- Self-assembly of azo DBC thin films generated via solvent vapor annealing or thermal annealing.

- LC textures are varied depending on composition of azo content in DBCs.

Acknowledgment: The author expresses his respectful gratitude to the Prof. Yang-Kyoo Han for guidance and 
financial support for this work. The author gratefully acknowledges use of facilities of Department of Chemistry at the University of Hanyang.

\section{References}

1. Han YK, Dufour B, Wu W, Kowalewski T, Matyjaszewski K. Synthesis and characterization of new liquid-crystalline block copolymers with p-cyanoazobenzene moieties and poly(n-butyl acrylate) segments using atom-transfer radical polymerization. Macromolecules. 2004;37:9355-65.

2. Wei R, Wang X, He Y. Synthesis of side-on liquid crystalline diblock copolymers through macromolecular azo coupling reaction. Eur Polym J. 2015;69:584-91.

3. Yu H. Recent advances in photoresponsive liquid-crystalline polymers containing azobenzene chormophores. J Mater Chem C. 2014;2:3047-54.

4. Yu H, Li J, Ikeda T, Iyoda T. Macroscopic parallel nanocylinder array fabrication using a simple rubbing technique. Adv Mater. 2006;18:2213-15.

5. Yu H, Iyoda T, Ikeda T. Photoinduced alignment of nanocylinders by supramolecular cooperation motions. J Am Chem Soc. 2006;128:11010-11.

6. Deng W, Albouy PA, Lacaze E, Keller P, Wang XG, Li MH. Azobenzene-containing liquid crystal triblock copolymers: synthesis, characterization and self-assembly behavior. Macromolecules. 2008;41:2459-66.

7. Zhao Y, He J. Azobenzene-containing block copolymers: the interplay of light and morphology enables new functions. Soft Matter. 2009;5:2686-93.

8. Kodota S, Aoki K, Nagano S, Seki T. Photocontrolled microphase separation of block copolymer in tow dimensions. J Am Chem Soc. 2005;127:8266-67.

9. Wang G, Tong X, Zhao Y. Preparation of azobenzene-containing amphiphilic diblock copolymers for light-responsive micellar aggregates. Macromolecules. 2004;37:8911-17.

10. Byun In-Joon, Lee M, Han YK. Synthesis of new azo-based liquid crystalline polymers and their selective sensing behaviors to alkali metal ions. J Polym Sci Part A Polym Chem. 2016;54:1713-23.

11. Li Z, Zhang Y, Zhu L, Shen T, Zhang H. Efficient synthesis of photoresponsive azobenzene-containing side-chain liquid crystalline polymers with high molecular weights by click chemistry. Polym Chem. 2010;1:1501-11.

12. Wang J, Wu B, Li S, Sinawang G, Wang X, He Y. Synthesis and characterization of photoprocessable lignin-based azo polymer. ACS Sustainable Chem Eng. 2016;4:4036-42.

13. Yu H. Photoresponsive liquid crystalline block copolymers: From photonics to nanotechnology. Prog Polym Sci. 2014;39:781-815.

14. Verploegen E, Zhang T, Jung YS, Ross C, Paula TH. Controlling the morphology of side chain liquid crystalline block copolymer thin films through variations in liquid crystalline content. Nano Lett. 2008;8:3434-40.

15. He X, Sun W, Yan D, Xie M, Zhang Y. Synthesis and characterization of side-chain liquid crystalline $A B C$ triblock copolymers with p-methoxyazobenzene moieties by atom transfer radical polymerization. J Polym Sci Part A Polym Chem. 2008;46:4442-50.

16. Ichimura K. Photoalignment of liquid-crystal systems. Chem Rev. 2000;100:1847-74.

17. Yager KG, Barrett C. All-optical patterning of azo polymer films. J Curr Opin Solid State Mater Sci. 2001;5:487-94.

18. Natansohn A, Rochon P. Photoinduced motions in azo-containing polymers. Chem Rev. 2002;102:4139-76.

19. Delaire JA, Nakatani K. Linear and nonlinear optical properties of photochromic molecules and materials. Chem Rev. 2000;100:1817-46.

20. Xie S, Natansohn A, Rochon P. Recent developments in aromatic azo polymers research. Chem Mater. 1993;5:403-11.

21. Freiberg S, Lagugné-Labarthet F, Rochon $P$, Natansohn A. Synthesis and characterization of a series of azobenzene-containing side-chain liquid crystalline polymers. Macromolecules. 2003;36:2680-8.

22. Ban JF, Chen S, Zhang HL. Synthesis and liquid crystalline behavior of side chain liquid crystalline polymers containing triphenylene discotic mesogens with different length flexible spacers. Chin J Polym Sci. 2015;33:1245-59.

23. Cojocariu C, Rochon P. Light-induced motions in azobenzene-containing polymers. Pure Appl Chem. 2004;76:1479-97.

24. Allcock HR, Kim C. Liquid crystalline phosphazenes. High polymeric and cyclic trimeric systems with aromatics azo side groups. Macromolecules. 1989;22:2596-602.

25. Lee MJ, Ji HN, Han YK. Silicon-containing azo polymers with paired mesogens and their applications to optical memory media. J Polym Sci Part A Polym Chem. 2008;46:6734-45.

26. Xu J, Zhang W, Zhou NC, Zhu J, Cheng ZP, Xu Y, Zhu XL. Synthesis of azobenzene-containing polymers via RAFT polymerization and investigation on intense fluorescence from aggregates of azobenzene-containing amphiphilic diblock copolymers. J Polym Sci Part A Polym Chem. 2008; 46:5652-62.

27. Cui L, Zhao Y, Yavrian A, Galstian T. Synthesis of azobenzenecontaining diblock copolymers using atom transfer radical polymerization and the photoalignment behavior. Macromolecules. 2003;36:8246-52.

28. Tian Y, Watanabe K, Kong X, Abe J, lyoda T. Synthesis, nanostructures, and functionality of amphiphilic liquid crystalline block copolymers with azobenzene moieties. Macromolecules. 2002;35:3739-47.

29. Wang J, Wang S, Zhou Y, Wang X, He Y. Fast photoinduced large deformation of colloidal spheres from a novel 4-arm azobenzene compound. ACS App Mater Interfaces. 2015;7:16889-95.

30. Yu H, Iyoda T. Photocontrollable liquid-crystalline actuators. Adv Mater. 2011;23:2149-80.

31. Yu H, Kobayashi T, Yang H. Liquid-crystalline ordering helps block copolymer self-assembly. Adv Mater. 2011;23:3337-44.

Supplemental Material: The online version of this article (DOI: 10.1515/epoly-2017-0042) offers supplementary material, available to authorized users. 